\title{
Removal of RhB from aqueous solutions by two polyoxometalates adsorbents
}

\author{
Shunqiang Chen ${ }^{\mathrm{a}}$, Yutong $\mathrm{Di}^{\mathrm{a}}$,Yong $\mathrm{Li}^{\mathrm{a}}$, Feng $\mathrm{Li}^{\mathrm{a}}$, Taohai $\mathrm{Li}^{* \mathrm{a}}$ and Wei Cao ${ }^{\mathrm{b}}$ \\ ${ }^{a}$ College of Chemistry, Key Lab of Environment Friendly Chemistry and Application \\ in Ministry of Education, Xiangtan University, Xiangtan, 411105, China. \\ ${ }^{b}$ Nano and Molecular Systems Research Unit, University of Oulu, P. O. Box 3000, \\ FIN-90014, Finland
}

\begin{abstract}
$\left[\mathrm{Ru}\left(2,2^{\prime} \text {-bipy }\right)_{3}\right]_{3}\left(\mathrm{PW}_{12} \mathrm{O}_{40}\right)_{2}$ and $\left[\mathrm{Ru}\left(2,2^{\prime} \text {-bipy }\right)_{3}\right]_{2}\left(\mathrm{SiW}_{12} \mathrm{O}_{40}\right)$ were synthesized via chemical co-precipitation method using $\left[\mathrm{Ru}\left(2,2^{\prime}\right.\right.$-bipy) $\left.{ }_{3}\right] \mathrm{Cl}_{2}$ and polyoxometalates as reactants. The adsorption ability of absorbents was studied by removing $\mathrm{RhB}$ from aqueous solutions in different conditions such absorbent dose, initial dye and contact time. The RPW owns better adsorption ability than the RSI, with a high adsorbing rate of $99 \%$ for the $\mathrm{RhB}$ under the optimized conditions (10mg/L, 100mg, 30min).

Keywords: Functional; Adsorbent; Polyoxometalates; Chemical coprecipitation method; Porous materials
\end{abstract}

* Correspondence Author. Tel.: +86-731-58292202; fax: +86-731-8292251;

E-mail address:hnlth@xtu.edu.cn 


\section{Introduction}

Each minute, a large amount of dyes, either colorless or coloured ones, is being discharged in wastewater from textile and printing industries. [1-3]. Among10, 000 kinds of commercial dyes[4], only few toxic and carcinogenic dyes [5] can be biodegraded, while others remain hazardous because of complex chemical composition. Rhodamine $\mathrm{B}(\mathrm{RhB})$ is one of the stable coloured composites that have widely used in typing paper, jute, leather, straw and so on. To deal with its possible spreading harms, various decontamination routes have been developed [6-13]. However, the large amount of wastewater and its rapid streams ask for instant water treatments in exhaust systems. Therefore, the effective adsorbents for the dye are demanded. So far, commercial available chemicals activated carbon [14] and polymeric porous materials frameworks [15] have been applied as the removal carriers. However, these compounds suffer from either low or limit adsorption capacity or inefficient extraction. Recent studies show metal-organic frameworks (MOFs) are advanced in large surface areas yielding remarkable capabilities of adsorption [16-17]. Similar to the MOFs, the polyoxometalates (POMs) also have special structures and wide potential applications in many areas such as catalysis, magnetism, separations and gas storage [18-19]. Therefore, many POMs have been developed in recent years [20-23]. Thus, a common functionality is denominated within the specialties by combining the POMs to the MOFs.

Recently, the N-containing ligand has attracted increasing interest in the 
building of POM-based MOF because of their flexibility and conformational freedom. Forexample, $\left[\mathrm{Cu}_{2}\left(\mathrm{~L}_{2}\right)_{3}\left(\mathrm{SiW}_{12} \mathrm{O}_{40}\right)\left(\mathrm{H}_{2} \mathrm{O}\right)_{6}\right] \cdot 6 \mathrm{H}_{2} \mathrm{O}[24],[(1,4-$ bis(1,2,4-triazol-1-yl)butane )$\left.\left(\mathrm{H}_{3} \mathrm{PW}_{12} \mathrm{O}_{40}\right)\right] \cdot 6 \mathrm{H}_{2} \mathrm{O}[25]$. However, there exist obvious limitations for these rigid or semi-rigid N-containing ligands for forming high-dimensional and novel topological structures, which may mainly rest on their rigid backbones. Moreover POM-based MOF has been rarely explored in the field of adsorbents for removing dye from wastewater.

Polyoxometalates (POMs) as one kind of significant metal-oxide clusters with high negative charge and abundant topologies, which improves the POMs to adsorb cationic dyes. However, the recovery and reusability of POMs are hindered by their high solubility, low specific area, and poor stability. MOF can provide large pore sizes and surface area. To overcome these drawbacks, metal-organic frameworks (MOFs) have been used to anchor POMs to create hybrid heterogeneous materials.

To meet urgent needs for water purification and benefit the potential adsorbents, we developed a coprecipation method to form the POM-MOF complexes of $\left[\mathrm{Ru}\left(2,2^{\prime} \text {-bipy }\right)_{3}\right]_{3}\left(\mathrm{PW}_{12} \mathrm{O}_{40}\right)_{2}(\mathrm{RPW})$ and $\left[\mathrm{Ru}\left(2,2^{\prime} \text {-bipy }\right)_{3}\right]_{2}\left(\mathrm{SiW}_{12} \mathrm{O}_{40}\right) \quad(\mathrm{RSI})$, and utilized them as adsorbents for RhB removal. Results show that under optimized conditions, $85 \%$ of the dye can be adsorbed by the complexes within 5 minutes, serving a practical route for dye removal in industry sewages.

\section{Experimental}

\subsection{Material and synthesis}


The $\left[\mathrm{Ru}\left(2,2^{\prime} \text {-bipy }\right)_{3}\right] \mathrm{Cl}_{2}$ was prepared following the previously reported steps [26]. The $\left[\mathrm{Ru}\left(2,2^{\prime} \text {-bipy }\right)_{3}\right] \mathrm{Cl}_{2}(0.769 \mathrm{~g})$ was added into deionized water and dissolved in a big beaker of $200 \mathrm{~mL}$ to get the solution. The pre-dissolved $\mathrm{H}_{3} \mathrm{PW}_{12} \mathrm{O}_{40}(1.997 \mathrm{~g}$ in $50 \mathrm{~mL})$ and $\mathrm{H}_{4} \mathrm{SiW}_{12} \mathrm{O}_{40}(1.731$ gin $50 \mathrm{~mL})$ solutions were added into the beaker at $80^{\circ} \mathrm{C}$ water bath and stirred for $1 \mathrm{~h}$. After that, the precipitations were centrifuged and washed with deionized water, anhydrous ethanol, ether until three times respectively. Finally, the precipitates were dried at $60^{\circ} \mathrm{C}$ for $24 \mathrm{~h}$. Element analysis through a Vario EL Element analyzer shows found values (in\%) are: C 14.49; H 0.819; N 3.377; C/N 4.277, close to the nominal ones of $\mathrm{C} 14.47 ; \mathrm{H} 0.964 ; \mathrm{N} 3.377$; $\mathrm{C} / \mathrm{N} 4.286$ for RPW. The found compositions of the RSI are: C 16.65; H 1.056; N 3.919; C/N 4.249 agreeing well to nominal ones of C 17.92; H 1.194; N 4.182; C/N 4.285.

\subsection{Characterizations}

Pore size and distributions were determined through a BET surface area analyzer. The chemical bonds on sample surfaces were detected by the Fourier transform infrared spectroscopy (FT-IR).Thermogravimetric analysis (TGA) curves were collected from a TGA 50 thermogravimetric analyzer at a heating rate of $20^{\circ} \mathrm{C} / \mathrm{min}$ in dynamic nitrogen atmosphere $(60 \mathrm{~mL} / \mathrm{min})$. The ultraviolet adsorption spectral analysis was performed on a Perkin Elmer Lambda 25 Ultra-violet spectrometer, while the element analysis on a Vario EL Element analyzer. The crystalline structures of the prepared samples were analyzed by an X-ray diffractometer (XRD) (Rigaku, RINT Ultima-III, Japan) with the $\mathrm{Cu}-\mathrm{Ka}$ as incident radiation. The X-ray photoelectron spectroscopy (XPS) analysis was performed on a Perkin-Elmer PHI 
$5000 \mathrm{C}$ to verify the chemical states of the as-prepared samples.

\subsection{Dye adsorption measurements}

The adsorption capabilities of the as-prepared RPW and RSI were evaluated by adsorbing $\mathrm{RhB}$ under various conditions. Initial dye concentrations were tuned to 10 , 15 and 20mg/L with a fixed volume of $100 \mathrm{~mL}$. Different doses of adsorbents (40, 60, $80,100,120 \mathrm{mg}$ ) were add into the dyes. The MOF-POM powder and dye mixture were constantly stirred at a speed of $400 \mathrm{rpm}$, and the dye concentration was measured at different time intervals. The relative concentration of the $\mathrm{RhB}$ is given by $\mathrm{Y}(\mathrm{t})=\mathrm{C} / \mathrm{C}_{0}$, where $\mathrm{C}$ is the concentration at time $\mathrm{t}$, and $\mathrm{C}_{0}$ is the initial concentration of RhB. As a comparison, the adsorption test was also performed for the $\left[\mathrm{Ru}\left(2,2^{\prime} \text {-bipy }\right)_{3}\right]_{3} \mathrm{Cl}_{2}$.

The used RPW and RSI were separated from aqueous solution by filtration and then washed with distilled water and ethanol under ultrasound at room temperature to remove the RhB adsorbed. The re-generated RPW and RSI powder were dried overnight at $60^{\circ} \mathrm{C}$ under vacuum and reused for the next adsorption.

\section{Results and discussion}

The FT-IR spectra of adsorbents were described in Fig.1a. Comparing with the FTIR spectrum of bipy, the peak at $1640 \mathrm{~cm}^{-1}$ of 2, 2-bipy shifts to $1424 \mathrm{~cm}^{-1}$ in the absorbents. The bands observed at about $3415 \mathrm{~cm}^{-1}$ couldbe attributed to the stretching vibration of $\mathrm{N}-\mathrm{H}$. The trough around $1077 \mathrm{~cm}^{-1}$ represented the P-O stretching. Characteristic peaks around 978, 890 and $817 \mathrm{~cm}^{-1}$ of RPW were ascribed to $v(\mathrm{~W}=\mathrm{Od}), v(\mathrm{~W}-\mathrm{Ob}-\mathrm{W})$ and $v(\mathrm{~W}-\mathrm{Oc}-\mathrm{W})$ of the $\mathrm{PW}_{12} \mathrm{O}_{40}{ }^{3-}$ polyanion, respectively 
[27]. The characteristic peaks of RSI around 1052, 968, 916, 801 和 $754 \mathrm{~cm}^{-1}$ were attributed to $v(\mathrm{Si}-\mathrm{Oa}), \quad v(\mathrm{~W}-\mathrm{Od}), \quad v(\mathrm{~W}-\mathrm{Ob}-\mathrm{W})$ and $v(\mathrm{~W}-\mathrm{Oc}-\mathrm{W})$ of the $\mathrm{SiW}_{12} \mathrm{O}_{40}{ }^{4-}$ polyanion [27]. Materials keep the original Keggin structure. In the TGA curves at Fig. 1b, the RPW (RSI) loses $6.1 \%(7 \%)$ weight at the range of $25-700^{\circ} \mathrm{C}$ due to loss of coordinated water and free water molecules. A weight loss of $18.9 \%(23 \%)$ from $700{ }^{\circ} \mathrm{C}$ to $900{ }^{\circ} \mathrm{C}$ was found in accordance to the percentage of pyridine in RPW18.84\% (RSI 23.3\%). Moreover, RPW has a better thermal stability compared with RSI. These results were further confirmed by the weight loss derivative curves as shown in Fig. 1 (c). In general, the RPW and RSI are stable under their decomposition temperatures. However, the RSI undergoes a dramatic weight loss at around $600^{\circ} \mathrm{C}$, and reaches the top speed at $\sim 800^{\circ} \mathrm{C}$. On the contrary, the RPW keeps stable before $700^{\circ} \mathrm{C}$, after which, sudden decomposition starts. The specific surface area of RPW (RSI) prepared given by BET test was $45.319 \mathrm{~m}^{2} / \mathrm{g}\left(56.163 \mathrm{~m}^{2} / \mathrm{g}\right)$ with a pore diameter $9.703 \mathrm{~nm}(1.017 \mathrm{~nm})$.
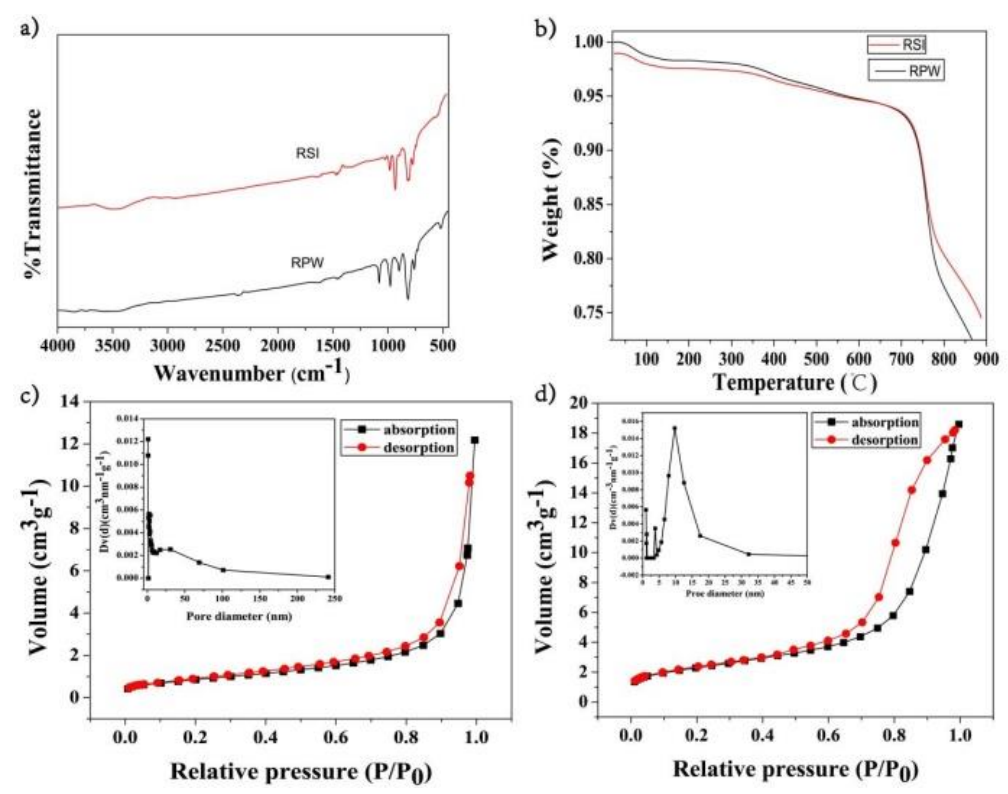
Fig. 1(a) FTIR of prepared adsorbents, (b) TGA of prepared adsorbents, (c) BET

$$
\text { patterns of RPW, (d) BET patterns of RSI. }
$$

The prepared crystalline structures of the samples were investigated by XRD patterns. As shown in Fig. 2, The RSI is rather not crystalized. The chemical states and elemental composition of adsorbents were further studied by the XPS and the detailed results are displayed in Figure 3 and 4 for the RPW and RSI, respectively. The spectral energies were calibrated by using the adventitious $\mathrm{C} 1 \mathrm{~s}$ peak at $284.8 \mathrm{eV}$. The XPS of the Ru orbital (Figure 3e) is detected at a binding energy around $284.7 \mathrm{eV}$ ( $\mathrm{Ru} 3 \mathrm{~d}$ ), and assigned to the $\mathrm{Ru}^{2+}$. Peaking at $134.38 \mathrm{eV}$ (Figure 3e), the phosphorus $2 p$ spectrum denotes the element is in the form of $\mathrm{P}^{5+}$. Figure $4 \mathrm{~d}$ demonstrates that the single peak of Si $2 \mathrm{p}$ is centered at $101.88 \mathrm{eV}$. Chemical states of the elements in the products are confirmed from the composites from the RPW and RSI. Characterizations through elemental analysis, TGA, FTIR, BET, DTG, XPS and XRD have confirmed that the purities and chemical states of the RPW and RSI.
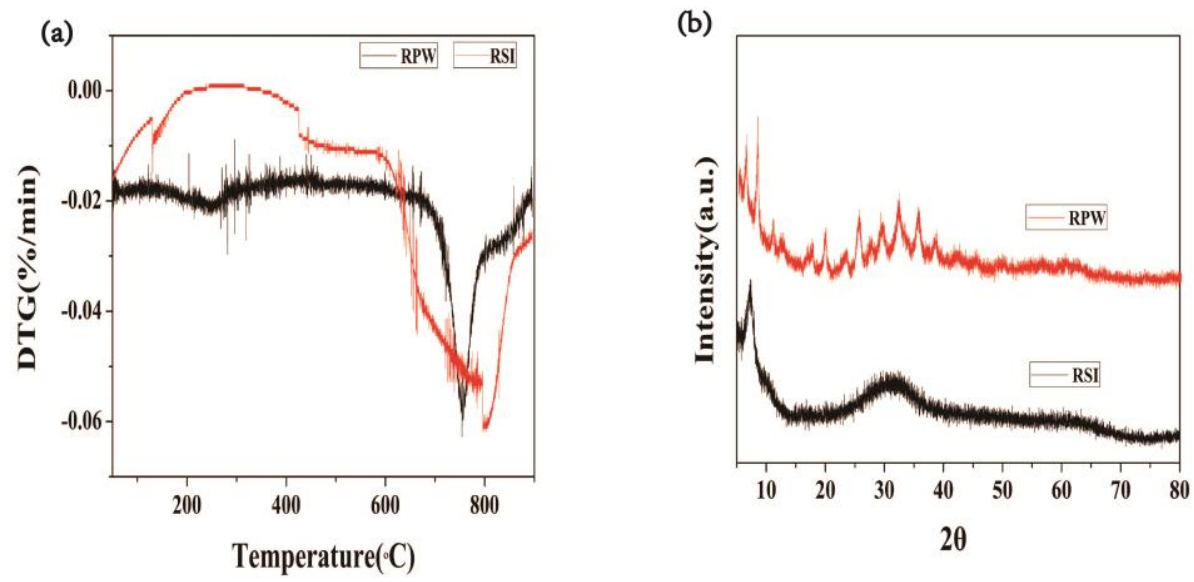

Fig. 2(a) DTG of prepared adsorbents, (b) XRD of prepared adsorbents 

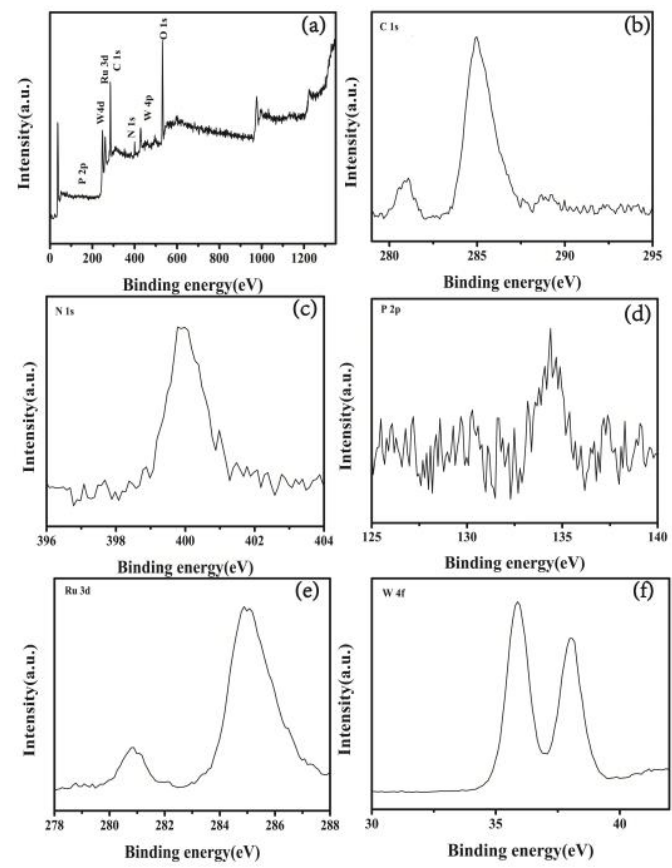

Fig. 3 XPS of prepared RPW. (a) survey spectrum and high-resolution XPS of (b) C 1s, (c) N 1s, (d) P 2p, (e) Ru 3d, (f) W 4f.
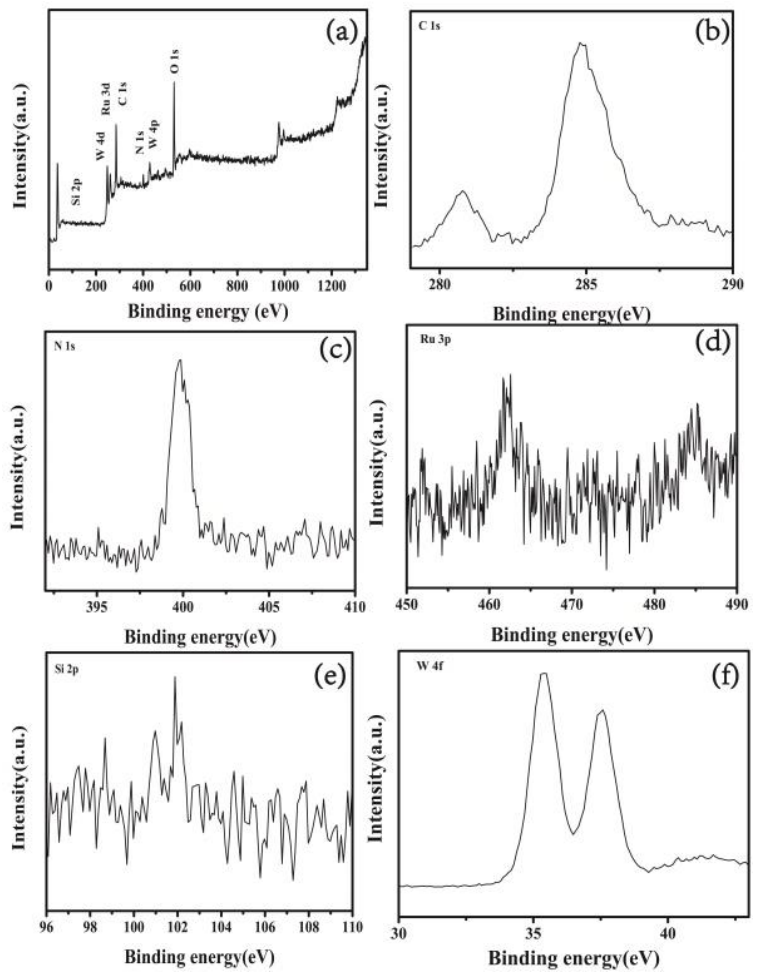

Fig. 4 XPS of prepared RSI. (a) survey spectrum and high-resolution XPS of

(b) C 1s, (c) N 1s, (d) Ru 3d, (e) Si 2p, (f) W 4f. 
Initial dye concentration strongly influences mass transfer resistances of the dye between aqueous phase and solid phase. We varied the adsorbate concentration within range of $10-20 \mathrm{mg} / \mathrm{L}$, and the adsorbing test results were shown in Fig 5a. The smallest concertation leads to fast adsorption rate of $80 \%$ in 5 minutes with the existence of RPW. The rate reached $99 \%$ at $30 \mathrm{~min}$. For solution of $20 \mathrm{mg} / \mathrm{L}$, the $\mathrm{RhB}$ was removed $80 \%$ at 30 minutes. As for the RSI, the removal rate reached more than $80 \%$ only at10 minutes. The better adsorption ability of the RSI is ascribed to the volumn filling theory [28]. Larger RPW's pore size (9.703nm) suits better RhB molecules $1.56 \mathrm{~nm}^{*} 1.35 \mathrm{~nm} * 0.42 \mathrm{~nm}[29]$ adsorptions than the one from the RSI $(1.017 \mathrm{~nm})$.
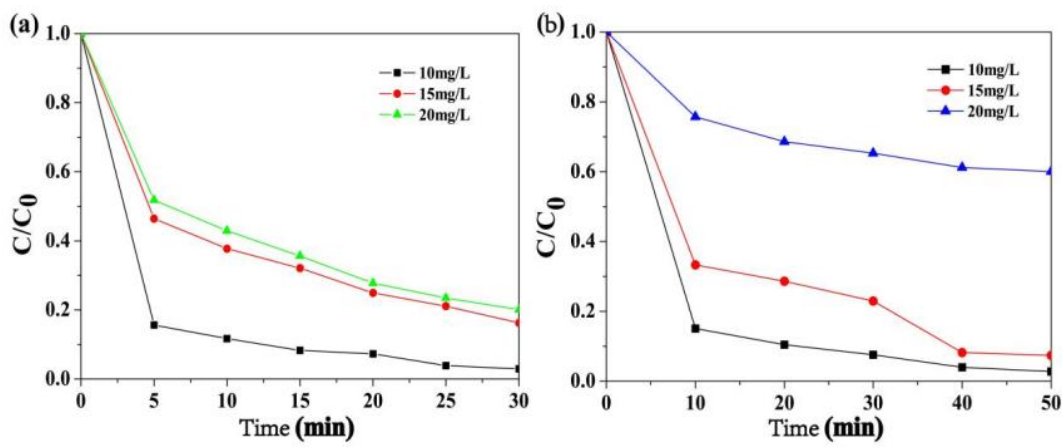

Fig 5. Variation of dye removal rate for different initial concentrations of $\mathrm{RhB}, \mathrm{pH}$ :

$7.0 \pm 0.1$, stirrer speed: $400 \mathrm{rpm}$ and temperature of $25 \pm 2{ }^{\circ} \mathrm{C}$ (a) RPW (b) RSI.

Influence of adsorbent dosage was investigated via changing the amount within40-120 mg but using the same adsorbate concentration of $10 \mathrm{mg} / \mathrm{L}$. The removal ratio of dye increases with the amount of the adsorbents. This is not surprising since larger mesopore and more adsorption sites exist at samples with larger quantity. A maximum removal percentage reaches $99 \%$ at doses of 100 and 120 mg, where the adsorption sites which remains unsaturated for the dyes [30]. The 
reasons of the same adsorbent with different effects on removal of dyes related to the structure of the dye molecules and the structure of the solid material. Firstly, POMs are a kind of hydrophilic metal-oxo cluster compounds, which allows the ingress and egress of the dye molecules. Secondly, POMs with a large number of negative charges have a stronger force with the positive charges of dyes.
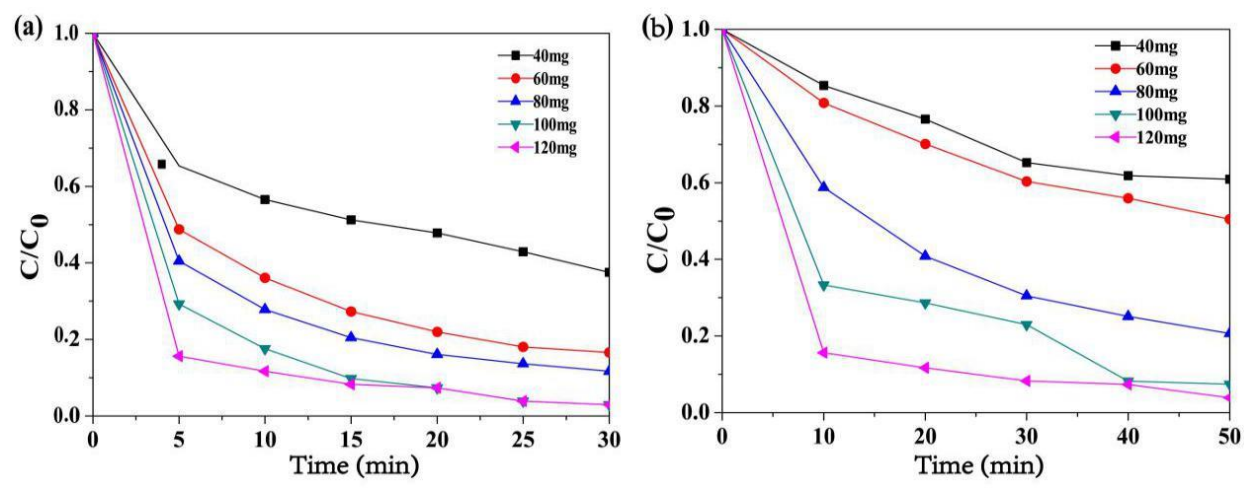

Fig 6. Effect of adsorbent dose on dye removal. Dye concentration: $10 \mathrm{mg} / \mathrm{L} \mathrm{pH:} 7.0$ \pm 0.1 , stirring speed: $400 \mathrm{rpm}$ and temperature of $25 \pm 2{ }^{\circ} \mathrm{C}$ (a) RPW, (b) RSI.

The adsorbents achieves the adsorption of $67.2 \mathrm{mg} / \mathrm{g} / \mathrm{h}(\mathrm{RPW})$ and $12.72 \mathrm{mg} / \mathrm{g} / \mathrm{h}(\mathrm{RSI})$. According to literatures, the RPW's value is much higher than the bio-adsorbents of neem sawdust $(4.71 \mathrm{mg} / \mathrm{g} / \mathrm{h})$ [31] and sugarcane dust $(6.48 \mathrm{mg} / \mathrm{g} / \mathrm{h})$ [32]. It also has better adsorption ability than the latest developed complex of $\left.[\mathrm{Ni} \text { (bipy })_{2}\right]_{2}\left(\mathrm{HPW}_{12} \mathrm{O}_{40}\right)[7]$. The present result tops the adsorbent abilities to the best of our knowledge.

We also tested the reusability of RPW and RSI samples. Figure 7 shows the adsorption ability of RhB for the successive four cycles. After four cycles, RPW and 
RSI still kept significant adsorption capacity of $98 \%$, confirming that the absorbents have good adsorption performance.
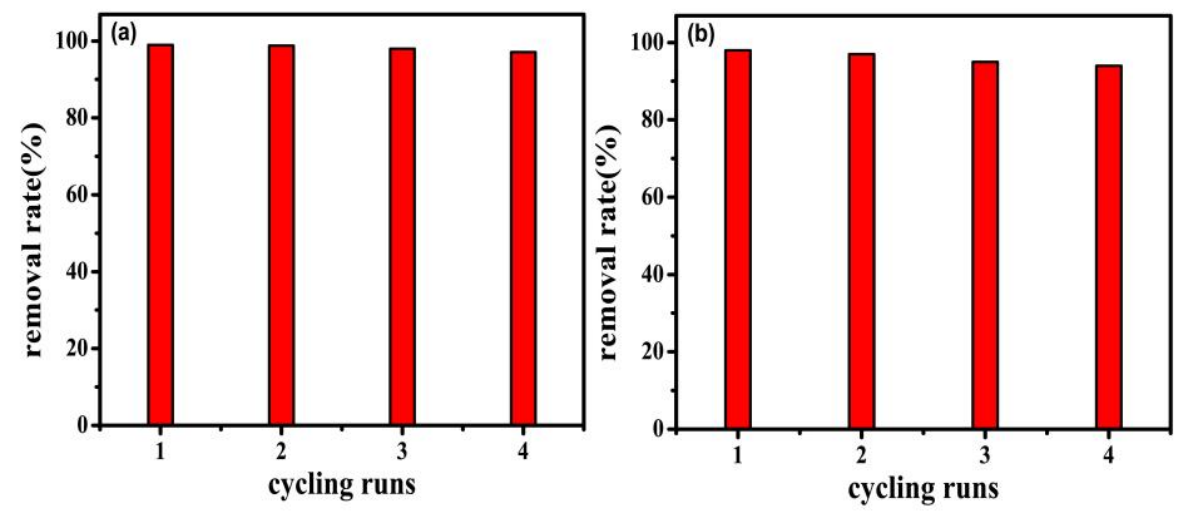

Fig 7. Cycling runs of (a) RPW and (b) RSI for the removal rate of RhB.

The pseudo-first-order kinetic model was employed to predict the adsorption kinetics of dyes [33]. A linear form of pseudo-first-order model is described by Lagergren in the form of [34]

$\log \left(q_{e}-q_{t}\right)=\log q_{e}-\left(k_{1} / 2.303\right) t$

Here $q_{t}$ was the adsorbed amount of dye at time $t(\mathrm{mg} / \mathrm{g})$, and $k_{1}$ is the equilibrium rate constant of pseudo-first-order adsorption $\left(\mathrm{min}^{-1}\right)$. The plot $\log \left(q_{e}-q_{t}\right)$ versus $t$ was a straight line (Fig. 8). The correlation coefficients were higher, indicating the pseudo-first-order model is sufficient in predicting kinetics of $\mathrm{RhB}$ adsorption onto RPW and RSI. 

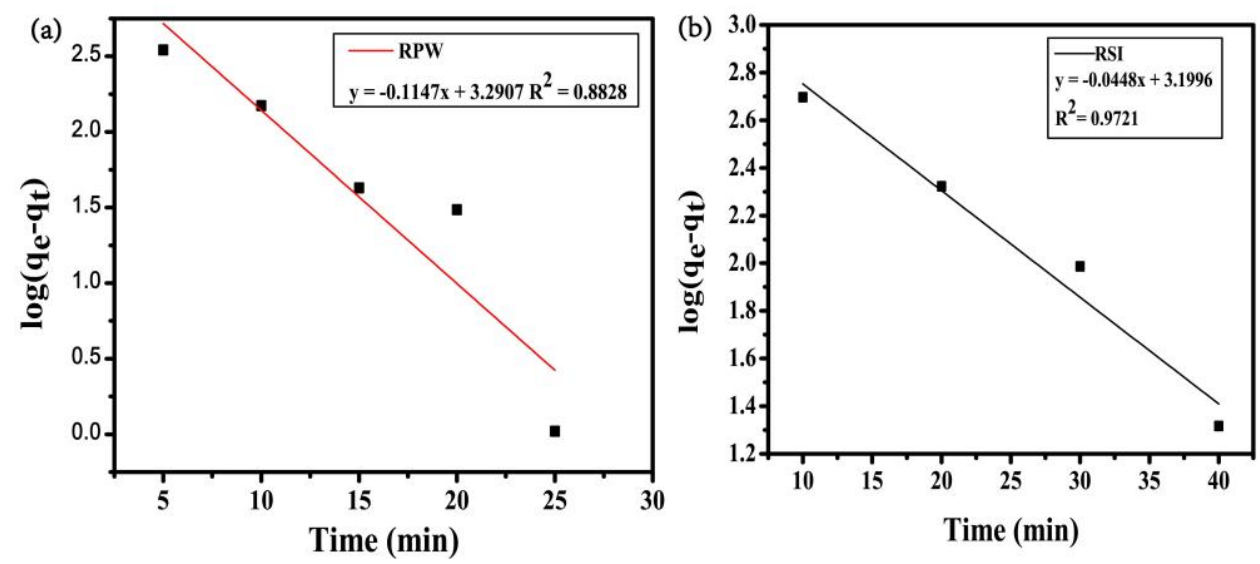

Fig 8. The plot $\log \left(\mathrm{q}_{\mathrm{e}}-\mathrm{q}_{\mathrm{t}}\right)$ versus t: (a) RPW and (b) RSI. Dye concentration: 10 $\mathrm{mg} / \mathrm{L}$, adsorbent dosage: 100mg.

\section{Conclusion}

In summary, we successfully synthesized MOF-POM complexes by using a simple co-precipitation method. Thanks to the joint functionalities, the complexes possess superior adsorption capacity for the toxic dye removal, and sustainable reusability. It is hoped that the simple and high-yielding preparation will finally enable the cheap MOF-POM complexes potentials as the high-performance but low-cost adsorbents for practical wastewater purification.

\section{Acknowledgements}

The authors acknowledge with thanks the financial support of the National Natural Science Foundation of China (21601149) and Scientific Research Fund of Hunan Provincial Education Department, China (16B253), the Open Project Program of State Key Laboratory of Structural Chemistry, China (No. 20150018) and Hunan 2011 Collaborative Innovation Center of Chemical Engineering \& Technology with 
Environmental Benignity and Effective Resource Utilization. W. Cao acknowledge financial support from EU Region Development Foundation, and the Council of Oulu Region.

\section{References}

[1] I.M. Banat, P. Nigam, D. Singh, R. Marchant. Bioresour. Technol. 58 (1996) 217-227.

[2] M.D.L Cruz, S.O. Alfaro. Solid State Sci. 11 (2009) 829-835.

[3] D. Pokhrel, T. Viraraghavan. Sci. Total Environ. 33 (2004) 37-58.

[4] S. Wang, Y. Boyjoo, A. Choueib. Chemosphere. 60 (2005) 1401-1407

[5] R. Gong, M. Li, C. Yang, Y. Sun, J. Chen. J. Hazard. Mater. 121 (2005) 247-250

[6] C. Yang, F. Li, M. Zhang, T. Li, W. Cao. J. Mol. Cataly. A: Chem. 423 (2016) 1-11.

[7] F. Li, C.Y. Yang, Q.G. Li, W. Cao, T.H. Li. Mat. Lett. 145 (2015) 52-55.

[8] Y. Kofuji, S. Ohkita, Y. Shiraishi, H. Sakamoto, S. Tanaka, S. Ichikawa, T. Hirai, ACS Catal. 6 (2016) 7021-7029.

[9] K.R. Reddy, V.G. Gomes, M. Hassan, Mater. Res. Exp. 1(2014) 015012.

[10] A.M. Showkat, Y.P. Zhang, M.S. Kim, A.I. Gopalan, K.R. Reddy, K.P. Lee, K. P. Bull, Korean Chem. Soc. 28 (2007) 1985-1992.

[11] K.R. Reddy, K.V. Karthik, S.B.B. Prasad.et al., Polyhedron. 120(2016) 169-174.

[12] K.R. Reddy, M. Hassan, V.G. Gomes. Appl. Catal. A: Gen. 489 (2015) 1-16.

[13] K.R. Reddy, K. Nakata, T. Ochiai, T. Murakami, D.A. Tryk, A. Fujishima, J. Nanosci. Nanotechnol. 11 (2011) 3692-3695.

[14] A.J. Romero-Anaya, M.A. Lillo-Ródenas. Carbon. 48 (2010) 2625-2633.

[15] K. Hamada, T. Kaneko, M.Q. Chen, M. Akashi. Chem. Mater. 19 (2007) 1044-1052.

[16] H. Wu, W. Zhou, T. Ylidirim. J. Am. Chem. Soc. 129 (2007) 5314-5315.

[17] P. Krawiec, M. Kramer, M. Sabo, R. Kunschke, H. Fröde, S. Kaskel. Adv. Eng.Mater.8 (2006) 293-296.

[18] R. Banerjee, A. Phan, B. Wang, C. Knobler, H. Furukawa, M. O’Keeffe, O.Yaghi. Science. 319 (2008) 939-943. 
[19] N.W. Ockwig, O. Delgado-Friedrichs, M. O'Keefe, O.M. Yaghi. Acc. Chem. Res. 38 (2005) $176-182$.

[20] R. Noguchi, A. Hara, A. Sugie, K. Nomiya. Inorg. Chem. Commun. 9 (2006) 355-359.

[21] K. Nomiya, T. Yoshida, Y. Sakai, A. Nanba, S. Tsuruta. Inorg. Chem. 49 (2010) 8247-8254.

[22] Y.F. Song, H. Abbas, C. Ritchie, N. McMillian, D.L. Long, N. Gadegaard, L.Cronin. J. Mater. Chem. 17 (2007) 903-908.

[23] Q.G. Zhai, X.Y. Wu, S.M. Chen, Z.G. Zhao, C.Z. Lu. Inorg. Chem. 46 (2007) 5046-5058.

[24] X.L. Wang, C. Xu, H.Y. Lin, G.C. Liu, S.Yang, Q. Gao, A.X. Tian. CrystEngComm. 14 (2012) 5836

[25] X.L. Wang, D. Zhao, A.X. Tian, J. Ying. CrystEngComm. 15(2013) 4516.

[26] S. Bhaduri, N.Y. Sapre. J. Chem. Soc. Dalton. Trans. 12 (1981) 2585.

[27] A.X. Yan, S. Yao, Y.G. Li, Z.M. Zhang, Y. Lu, W.L. Chen, E.B. Wang. Chem. Eur. J. 20 (2014) 6927-6933

[28] C.R. Clarkson, R.M. Bustin, J.H. Levy. Carbon. 35 (1997) 1689-1705.

[29] C.C. Wang, J.R. Li, X.L. Lv, Y.Q. Zhang, G.S. Guo. Energy Enviro. Sci.7 (2014) 2831-2867.

[30] C. Raji, T.S Anirudhan. Ind. J. Chem. Technol. 4 (1997) 157-162.

[31] S.D. Khattri, M.K. Singh. Adsorpt. Sci. Technol. 17 (1999) 269-282.

[32] S.D. Khattri, M.K. Singh. J. Hazard. Mater. 167 (2009) 1089-1094.

[33] M. Ghaedi, A. Hassanzadeh, K.S. Nasiri. J. Chem. Eng. Data 56 (2011) 2511-2520.

[34] M. Arami, N.Y. Limaee, N.M. Mahmoodi, N.S. Tabrizi. J. Colloid Interface Sci. 288(2005) $371-376$. 